\title{
Genetic variation among biofortified and late blight tolerant potato (Solanum tuberosum L.) (mini tuber) production in Bangladesh
}

\author{
Md. Mushfiqur Rahman ${ }^{1 *}$, Md. Nurul Amin ${ }^{1}$, Md. Harunor Rashid ${ }^{2}$, Md. Mazadul Islam², Bimal \\ Chandra Kundu ${ }^{2}$, Md. Mohi Uddin ${ }^{3} \&$ E.H.M. Shofiur Rahaman ${ }^{4}$ \\ ${ }^{1}$ Breeder Seed Production Centre, ${ }^{2}$ Tuber Crop Research Centre, ${ }^{3}$ Breeder Seed Production Centre, Bangladesh Agricultural Research Institute, \\ Debiganj, Panchagarh-5020, Bangladesh \\ ${ }^{4}$ International Potato Center (CIP), Dhaka, Banani, Dhaka-1213, Bangladesh \\ *Email: mushfiqsau1693@gmail.com
}

\section{ARTICLE HISTORY}

Received: 14 March 2021

Accepted: 29 April 2021

Available online: 01 July 2021

\section{KEYWORDS}

Accessions

CIP

Micronutrient

Principal

Traits

\section{ABSTRACT}

Biofortified potato could contribute a major role in food security for millions of people. It could help to alleviate worldwide micronutrient malnutrition. An experiment was carried out during 2019-2020 growing season with 49 accessions following randomized complete block design with three replications in order to evaluate and classify agro-morphological traits in Breeder seed production centre (BSPC), Debiganj, Panchagarh. Eight quantitative characters i.e. germination percent, foliage coverage, stem number per hill, plant height, plant vigor, tuber number per plant, tuber weight per plant, yield per plant were measured. Principal components (PC) analysis showed three components explained 72.16 $\%$ of the total variation among traits. The first PC assigned $35.22 \%$ and the second PC assigned $58.47 \%$ of total variation between traits. The first PC was more related to yield per plant and weight of tuber. Forty-nine germplasm was placed on three cluster based on cluster analysis using a hierarchical classification (HCA). All accessions were discriminated and high morphological variation was observed. Thus, the outcomes of principal component analysis used in the study have revealed the high level of genetic variation and the traits contributing to the variation were identified. CIP403, CIP404, CIP405, CIP413 and CIP445 accessions identified as superior based on cluster relationship and PCA bi-plot.

\section{Introduction}

Micronutrient deficiency is a major problem, which is often termed as hidden hunger. It affects over two billion people worldwide (1). Potato could contribute to a major role in food security for millions of people. Worldwide micronutrient malnutrition could be eradicated by serving biofortified potato and ensuring nutrient security. Biofortification is the development of micronutrient or vitamin-rich crops using the traditional crop improvement practices as well as modern biotechnology tools. It is a more sustainable and cost-effective method than the food supplementation, fortification and diet diversification (2). The most popular and earliest example of a success story of transgenic biofortification research is the development of Golden Rice or $\beta$-carotene rich rice. Golden rice transgenic lines have been under field trial in the Philippines (transgenic of RC-28), Bangladesh (transgenic of BRRI Dhan-29) and will certainly help to fight against iron deficiency (3). Potato is one of the most important tuber crops grown in Bangladesh for its high production, high nutritional values, easy digestibility and many industrial uses (4). According to a researcher (5), potato is considered as a promising candidate crop for feeding the hungry people of the world after rice and wheat. Genetic diversity and variability in a population of certain crop species is a prerequisite for an effective plantbreeding programme. A morphological tool for an efficient choice of parents is needed to initiate a hybridization programme. Principal Component Analysis (PCA) is a statistical method that attempts to describe the total variation in the multivariate sample using fewer variables than in the original data set (6). When a large number of desirable traits are involved, the application of PCA is recommended to facilitate the selection of the most relevant variables. The PCA identifies plant traits that distinguish the distinctness among the chosen genotypes for hybridization. A group of researchers (7), mentioned that these techniques aid in the classification of a population into groups of distinct orders based on similarities and thus assisting to choose parents for hybridization. The researcher and their associates (8), reported that PCA reduced the original five sensory attributes into two

(c) Rahman et al (2021). This is an open-access article distributed under the terms of the Creative Commons Attribution License, which permits unrestricted use, distribution and reproduction in any medium, provided the original author and source are credited (https://creativecommons.org/licenses/by/4.0/). 
independent components, which accounted for $66 \%$ of the total variability in the data. The knowledge of genetic diversity helps to avoid duplicates in the collection provides a better classification and assist in breeding selection (9). The PCA has been used to partition observed agronomic variations in genotypes of many crops such as sweet potato landraces (7), rubber, rice, sesame and durum wheat (10-13). Therefore, PCA is a very useful tool to classify genotypes of different crops. For a successful breeding programme, genetic diversity and variability are useful tool for an efficient choice of parents for hybridization to develop high-yield potential cultivars. In addition, multiple nutrition traits along with late blight tolerance will be possible to combine in a single cultivar along with high yield through hybridization (14). The purpose of this study was to investigate genetic divergence through PCA in biofortified and late blight tolerant CIP potato germplasm and the selection of desirable accession for hybridization in Bangladesh.

\section{Materials and Methods}

Forty-nine (thirty-nine high yielding biofortified and ten late blight tolerant) potato germplasm (Table 1) collected from Tuber Crop Research Centre (TCRC) of Bangladesh Agricultural Research Institute (BARI) and were evaluated during the 2019-20 growing season at Breeder Seed Production Centre (BSPC), Debiganj, Panchagarh, Bangladesh. The origin of those biofortified potato mini-tuber germplasm was collected from CIP, Bangladesh. The unit plot size was $3 \mathrm{~m} \times 3 \mathrm{~m}$ with 3 replications. The plantlet was planted with a spacing of $40 \mathrm{~cm} \times 25 \mathrm{~cm}$ during the first week of November 2019. Fertilizers were applied @ 325-220-250-120 kg per hectare of urea, TSP, MOP and gypsum respectively. Intercultural operations like earthing-up and weeding were done as and when required. The experimental plots were irrigated frequently to maintain adequate soil moisture and to keep the soil cool. For each accession, ten (10) randomly selected plants were used for the scoring of the characters. Data were collected on plant stand at 45 days after planting (DAP) and foliage coverage (\%) at 45 DAP and plant height $(\mathrm{cm})$, stem number per plant, number of tubers per plant, the yield of tubers per plant (gm) and the grade of tubers (\%) were collected during harvest at 95 DAP. Quantification of morphological variability for Tuber skin color, tuber shape, flesh colour and tuber eye depth characters were done using the Shannon-Weaver Diversity Index (Supplementary Table 1 and Supplementary Table 2). The estimate of variability for each qualitative character was computed using the standardized Shannon-Weaver Diversity Index, designated as $\mathrm{H}^{\text {' }}$ and has the formula:

$$
\mathrm{H}^{\prime}=-\sum \mathrm{Pi}\left(\log _{2} \mathrm{Pi}\right) / \log _{2} \mathrm{n}
$$

Where $\mathrm{Pi}$ is the proportion of the total number of genotypes belonging to the ith class. Following the work of groups of researchers (15), the same formula was applied to the quantitative characters.

Mean data for each character was subjected to multivariate analyses using FactoMineR, "Factoextra" package and "Performance Analytics" (16-18) for correlation in $\mathrm{R}$ Studio. The magnitude of genetic diversity among forty-nine genotypes was determined by using $\mathrm{D}^{2}$ Mahalanobis genetic distance

Table 1. Origin and accession ID of CIP biofortified and late blight tolerant potato accessions

\begin{tabular}{|c|c|c|c|}
\hline Name & Accession ID & Percentage of accessions & Special character \\
\hline CIP-401 & CIP302534.17 & $393371.16 \times 396272.18$ & Late blight tolerant \\
\hline CIP-402 & CIP302551.26 & $393385.47 \times 393272.18$ & Late blight tolerant \\
\hline CIP-403 & CIP304079.10 & $393075.54 \times 800959$ & Late blight tolerant \\
\hline CIP-404 & CIP312507.311 & CIP391058.175 × CIP306416.68 & Iron and zinc rich \\
\hline CIP-405 & CIP312507.312 & CIP391058.175 × CIP306416.68 & Iron and zinc rich \\
\hline CIP-406 & CIP312535.032 & CIP392025.7 × CIP306416.68 & Iron and zinc rich \\
\hline CIP-407 & CIP312595.053 & CIP393073.179 × CIP306416.68 & Iron and zinc rich \\
\hline CIP-408 & CIP312609.247 & CIP393083.2 × CIP306416.68 & Iron and zinc rich \\
\hline CIP-409 & CIP312609.252 & CIP393083.2 × CIP306416.68 & Iron and zinc rich \\
\hline CIP-410 & CIP312633.155 & CIP393536.13 × CIP306416.68 & Iron and zinc rich \\
\hline CIP-411 & CIP312637.020 & CIP393536.13 × CIP306418.69 & Iron and zinc rich \\
\hline CIP-412 & CIP312637.069 & CIP393536.13 × CIP306418.69 & Iron and zinc rich \\
\hline CIP-413 & CIP312637.132 & CIP393536.13 × CIP306418.69 & Iron and zinc rich \\
\hline CIP-414 & CIP312682.005 & CIP394600.52 × CIP306416.68 & Iron and zinc rich \\
\hline CIP-415 & CIP312682.011 & CIP394600.52 × CIP306416.68 & Iron and zinc rich \\
\hline CIP-416 & CIP312682.042 & CIP394600.52 × CIP306416.68 & Iron and zinc rich \\
\hline CIP-417 & CIP312721.004 & CIP395017.229 × CIP306416.68 & Iron and zinc rich \\
\hline CIP-418 & CIP312721.029 & CIP395017.229 × CIP306416.68 & Iron and zinc rich \\
\hline CIP-419 & CIP312721.038 & CIP395017.229 × CIP306416.68 & Iron and zinc rich \\
\hline CIP-420 & CIP312721.163 & CIP395017.229 × CIP306416.68 & Iron and zinc rich \\
\hline CIP-421 & CIP312721.169 & CIP395017.229 × CIP306416.68 & Iron and zinc rich \\
\hline CIP-422 & CIP312721.212 & CIP395017.229 × CIP306416.68 & Iron and zinc rich \\
\hline CIP-423 & CIP312721.245 & CIP395017.229 × CIP306416.68 & Iron and zinc rich \\
\hline CIP-424 & CIP312725.001 & CIP395017.229 × CIP306418.69 & Iron and zinc rich \\
\hline CIP-425 & CIP312725.036 & CIP395017.229 × CIP306418.69 & Iron and zinc rich \\
\hline CIP-426 & CIP312725.041 & CIP395017.229 × CIP306418.69 & Iron and zinc rich \\
\hline CIP-427 & CIP312725.047 & CIP395017.229 × CIP306418.69 & Iron and zinc rich \\
\hline CIP-428 & CIP312725.048 & CIP395017.229 × CIP306418.69 & Iron and zinc rich \\
\hline CIP-429 & CIP312725.052 & CIP395017.229 × CIP306418.69 & Iron and zinc rich \\
\hline
\end{tabular}




\begin{tabular}{|c|c|c|c|}
\hline CIP-430 & CIP312725.057 & CIP395017.229 × CIP306418.69 & Iron and zinc rich \\
\hline CIP-431 & CIP312725.067 & CIP395017.229 × CIP306418.69 & Iron and zinc rich \\
\hline CIP-432 & CIP312731.004 & CIP395017.242 × CIP306087.82 & Iron and zinc rich \\
\hline CIP-433 & CIP312735.051 & CIP395017.242 × CIP306416.68 & Iron and zinc rich \\
\hline CIP-434 & CIP312735.062 & CIP395017.242 × CIP306416.68 & Iron and zinc rich \\
\hline CIP-435 & CIP312735.105 & CIP395017.242 × CIP306416.68 & Iron and zinc rich \\
\hline CIP-436 & CIP312735.114 & CIP395017.242 × CIP306416.68 & Iron and zinc rich \\
\hline CIP-438 & CIP312751.025 & CIP395112.32 × CIP306418.69 & Iron and zinc rich \\
\hline CIP-439 & CIP312751.028 & CIP395112.32 × CIP306418.69 & Iron and zinc rich \\
\hline CIP-440 & CIP312763.441 & CIP395443.103 × CIP306416.68 & Iron and zinc rich \\
\hline CIP-441 & CIP312764.013 & CIP395443.103 × CIP306418.1 & Iron and zinc rich \\
\hline CIP-442 & CIP312767.014 & CIP395443.103 × CIP306418.69 & Iron and zinc rich \\
\hline CIP-443 & CIP312871.043 & CIP780278 × CIP306418.69 & Iron and zinc rich \\
\hline CIP-444 & CIP398098.570 & $393371.58 \times 392639.31$ & Late blight tolerant \\
\hline CIP-445 & CIP398190.200 & $393077.54 \times 392639.2$ & Late blight tolerant \\
\hline CIP-446 & CIP398192.213 & $393077.54 \times 392633.54$ & Late blight tolerant \\
\hline CIP-447 & CIP398192.553 & $393077.54 \times 392633.54$ & Late blight tolerant \\
\hline CIP-448 & CIP398208.219 & $393371.58 \times 392633.54$ & Late blight tolerant \\
\hline CIP-449 & CIP398208.620 & $393371.58 \times 392633.54$ & Late blight tolerant \\
\hline CIP-450 & CIP398208.670 & $393371.58 \times 392633.54$ & Late blight tolerant \\
\hline
\end{tabular}

statistics (19). Hierarchical clustering using Tocher's method, as described by (20) was followed for the grouping of genotypes into distinct clusters.

\section{Results and Discussion}

A wide range of agronomic traits has been evaluated in potato germplasm collections for their possible use in the improvement of potato cultivars. Therefore, the account of characters association between the traits themselves and with the yield is very significant for the breeding materials subjected to selection for high yielding genotypes (Fig. 1). Stronger positive and positive correlations were found between tuber yield and plant height $(r=0.34)$, main stems per hill $(r=0.13)$, the weight of tuber and yield $(\mathrm{r}=0.71)$, foliage coverage and tuber yield $(\mathrm{r}=0.32)$, plant vigor and plant height $(r=0.56)$, plant vigor and foliage coverage $(r=0.55)$, germination percentage and stem per hill $(\mathrm{r}=0.38)$, germination and foliage coverage $(r=0.29)$, tuber count and stem per hill $(r=0.40)$ (Fig. 1). These results revealed that any positive increase in such characters will boast the tuber yield. On the other hand, negative and significant correlations were found between tuber count and the weight of tuber $(r=-0.61)$ (Fig. 1). The magnitudes of correlation coefficients were classified as based on asterisk marks (Fig. 1). Single asterisk marks were considered average; double asterisk marks were considered strong; triple asterisk marks were considered as very strong correlations. The positive correlation which means the change of the two traits be in the same direction (increase or decrease) and the negative correlation which mean the increase in the first trait combined with a decrease in the second trait (or reverse).

Another researcher (21) found a positive significant correlation between tuber weight and tuber count. We found a negative correlation between tuber weight and tuber count $(r=-0.61)$. Other researchers (22) found similar results i.e., the significant correlation between tuber yield and tuber weight. PCA is commonly used to analyze phenotypic traits in crops and to select traits that contribute to genetic improvement (23). In PCA, only the first twocomponent axis had eigen values up to 4.68 (Table 2) presenting a cumulative variance of $58.47 \%$. Principal component one (PC1), with an eigen value of 2.82 , contributed $35.22 \%$ of the total variability, while PC2, with eigen value of 1.86 accounted for $58.47 \%$ of total variability observed among the 49 potato genotypes (Table 2). Another group of researchers (24) found similar results. They reported that the first three PC accounted for $71 \%$ of the total diversity whereas the first PCA accounted for $29.01 \%$. The first PC was more related to tuber yield per plant, tuber weight and the second PC was more associated with plant height, plant emergence/germination, plant vigor, foliage coverage, stems per hill and tuber count (Fig. 2). In addition, more variations were evident relatively in the traits, which were located on the first component (Fig. 2). The Germplasm located at quadrant four had wide variability (35.2\%) and most of the germplasm present in into cluster III (Fig. 3). Q1 and Q2 had least divergence and present in mostly cluster I. Quadrant Q3 had moderate variability present in cluster II.

The cluster analysis divided genotypes based on similarity and provided a hierarchical classification (HCA). The results obtained following HCA were shown as a dendrogram (Fig. 4) in which three welldefined clusters were visible. Based on the hierarchical clustering on principal components the 49 genotypes were grouped into three different clusters (Table 3 and Fig. 3). Cluster II contained the maximum number of twenty-two genotypes followed by cluster III having sixteen genotypes and cluster I having eleven genotypes (Fig. 3 and Table 3). On the basis of the cluster means, the important cluster was cluster II for percent germination, foliage coverage, stem per hill, plant height and plant vigor, cluster III for the weight of tuber and yield per plant. Cluster I had the lowest mean for germination percentage, foliage coverage, stem per hill, plant height, plant vigor, the weight of tuber, tuber count and yield per plant (Table 4). The dendrogram was cut with the most distance from the other groups and 49 cultivars were included in three clusters (Fig. 4). Researchers 


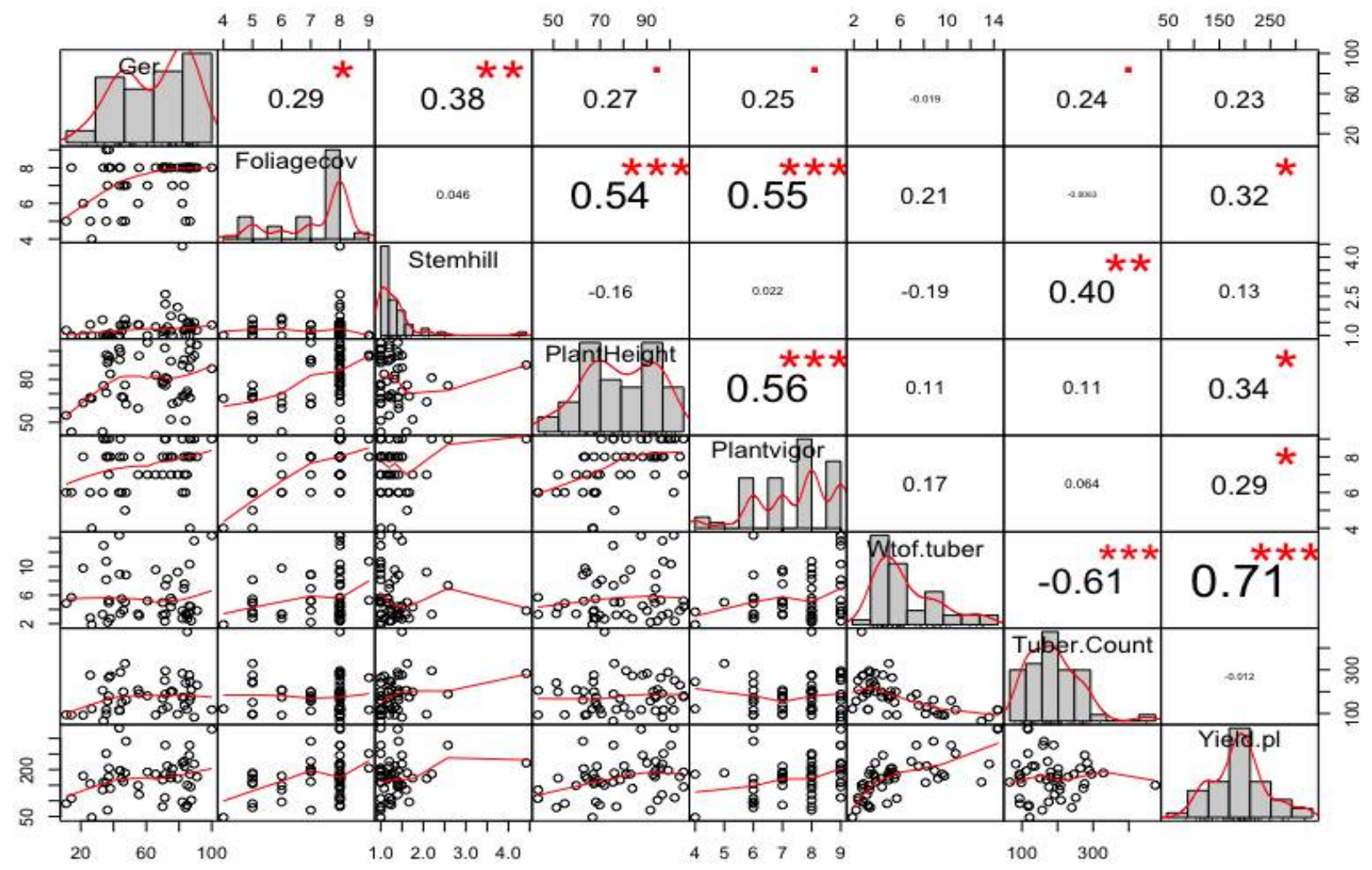

Fig. 1. Correlation coefficients among eight traits of 49 CIP biofortified and late blight tolerant potato genotypes.

(25), also found that the dendrogram obtained using highly variable morphological characters that separated 89 sweet potato genotypes into major clusters. About the distribution of tuber sizes, all the CIP clones showed a higher percentage of tubers size $25 \mathrm{~mm}$ and above (Table 5.). The quality of the seed depends on physiological age, uniformity and tuber size. The difference in tuber size is probably best explained by genetically different makeup of the TPS progeny. This is in agreement with (26). In addition, a researcher (27) reported that tuber size below $25 \mathrm{gm}$ can successfully be used as seed tuber for next season, which gives the same potential yield as seed tubers (25-50 gm) of a standard cultivar. The Shannon-Weaver Diversity Index has a value ranging

Table 2. Computed Eigen values with corresponding proportion

\begin{tabular}{cccc}
\multicolumn{4}{c}{ and cumulative explained variance } \\
\hline $\begin{array}{c}\text { Principal } \\
\text { component }\end{array}$ & Eigen Value & Variance & $\begin{array}{c}\text { Cumulative } \\
\text { variance }\end{array}$ \\
\hline 1 & 2.82 & 35.22 & 35.22 \\
\hline 2 & 1.86 & 23.24 & 58.47 \\
\hline 3 & 1.10 & 13.69 & 72.16 \\
\hline 4 & 0.71 & 8.82 & 80.97 \\
\hline 5 & 0.68 & 8.53 & 89.51 \\
\hline 6 & 0.42 & 5.22 & 94.73 \\
\hline 7 & 0.57 & 4.061 & 98.78 \\
\hline 8 & 0.31 & 1.2121 & 100 \\
\hline
\end{tabular}

from 0 to 1 , where 0 indicates the absence of diversity and 1 indicates maximum diversity (Supplementary Table 1 and Supplementary Table 2). The greater diversity in the studied materials will offer good scope for the improvement of potato through rational selection of parent's genotypes. Relatively more variations were evident in the traits, which were located on the first principal component. The above variables might be taken into consideration for the effective selection of parents during the hybridization programme. We selected CIP403, CIP404, CIP405, CIP413 and CIP445 accessions for their yield potentiality and tuber weight (Supplementary Fig. 1). The lines that are superior in terms of genetic diversity and agronomical properties during the improvement studies need to be selected (28). Similarly, another researcher (29) also selected nine genotypes among sixty-three potato genotypes in terms of maturity time, tuber shape plant height.

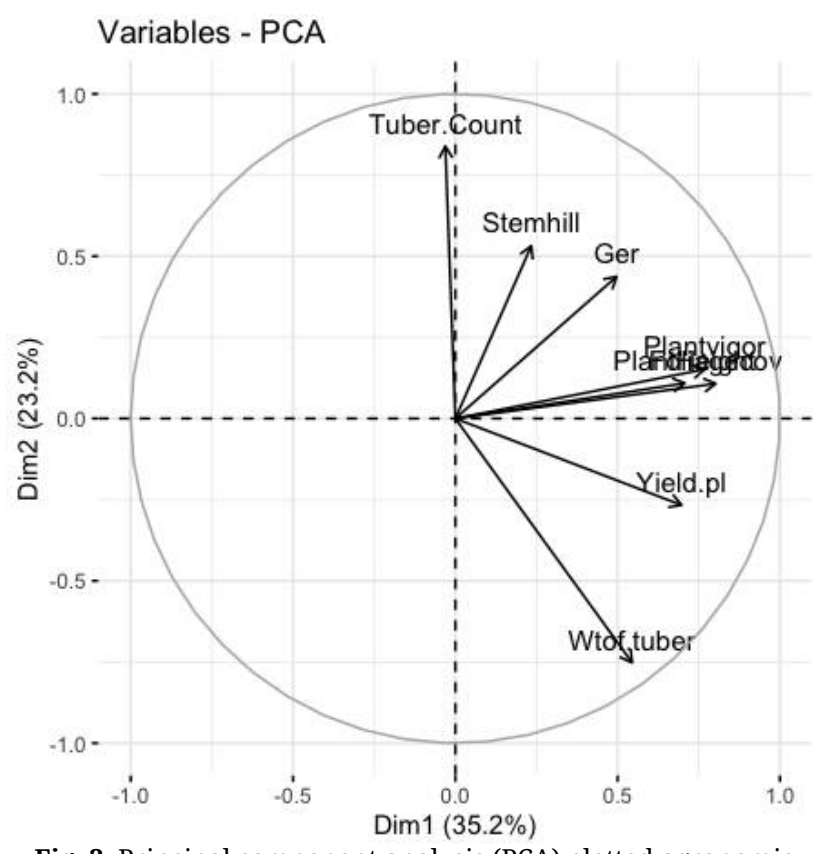

Fig. 2. Principal component analysis (PCA) plotted agronomic characters along the first two axis 


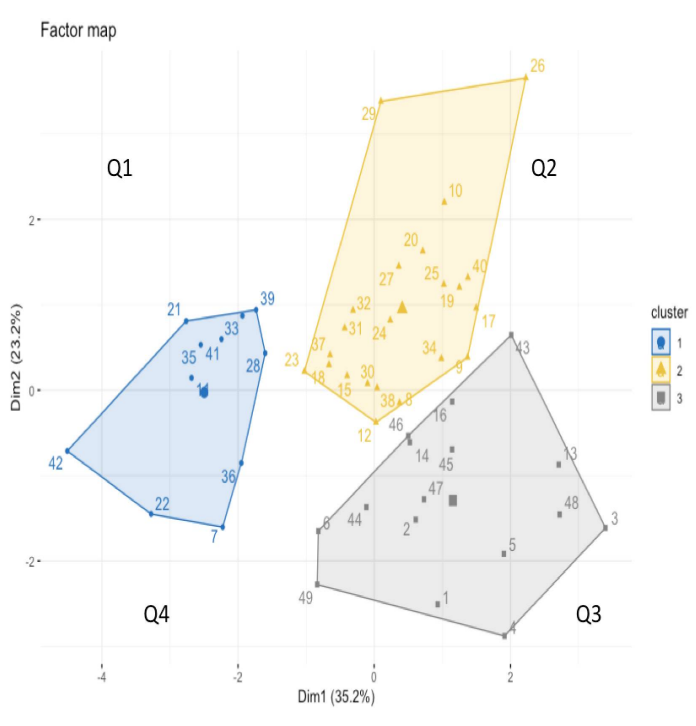

Fig. 3. Distribution of 49 biofortified and late blight tolerant potato germplasm in three clusters.
Table 3. Distribution of 49 CIP biofortified and late blight tolerant potato germplasm in three different clusters

\begin{tabular}{|c|c|c|}
\hline Cluster & Number & Name of Accessions \\
\hline I & 11 & $\begin{array}{l}\text { CIP407, CIP411, CIP421, CIP422, CIP428, } \\
\text { CIP433, CIP435, CIP436, CIP 440, CIP442 } \\
\text { and CIP443 }\end{array}$ \\
\hline II & 22 & $\begin{array}{l}\text { CIP408, CIP409, CIP410, CIP412, CIP415, } \\
\text { CIP417, CIP418, CIP419, CIP420, CIP423, } \\
\text { CIP424, CIP425, CIP426, CIP427, CIP429, } \\
\text { CIP430, CIP431, CIP432, CIP434, CIP438, } \\
\text { CIP439 and CIP441 }\end{array}$ \\
\hline III & 16 & $\begin{array}{l}\text { CIP401, CIP402, CIP403, CIP404, CIP405, } \\
\text { CIP406, CIP413, CIP414, CIP416, CIP444, } \\
\text { CIP445, CIP446, CIP447, CIP448, CIP449 } \\
\text { and CIP450 }\end{array}$ \\
\hline
\end{tabular}

and will be used as parental material for fixation of heterosis in potato improvement programme.

\section{Acknowledgements}

This work received financial support from the German Federal Ministry for Economic Cooperation and Development (BMZ) commissioned and

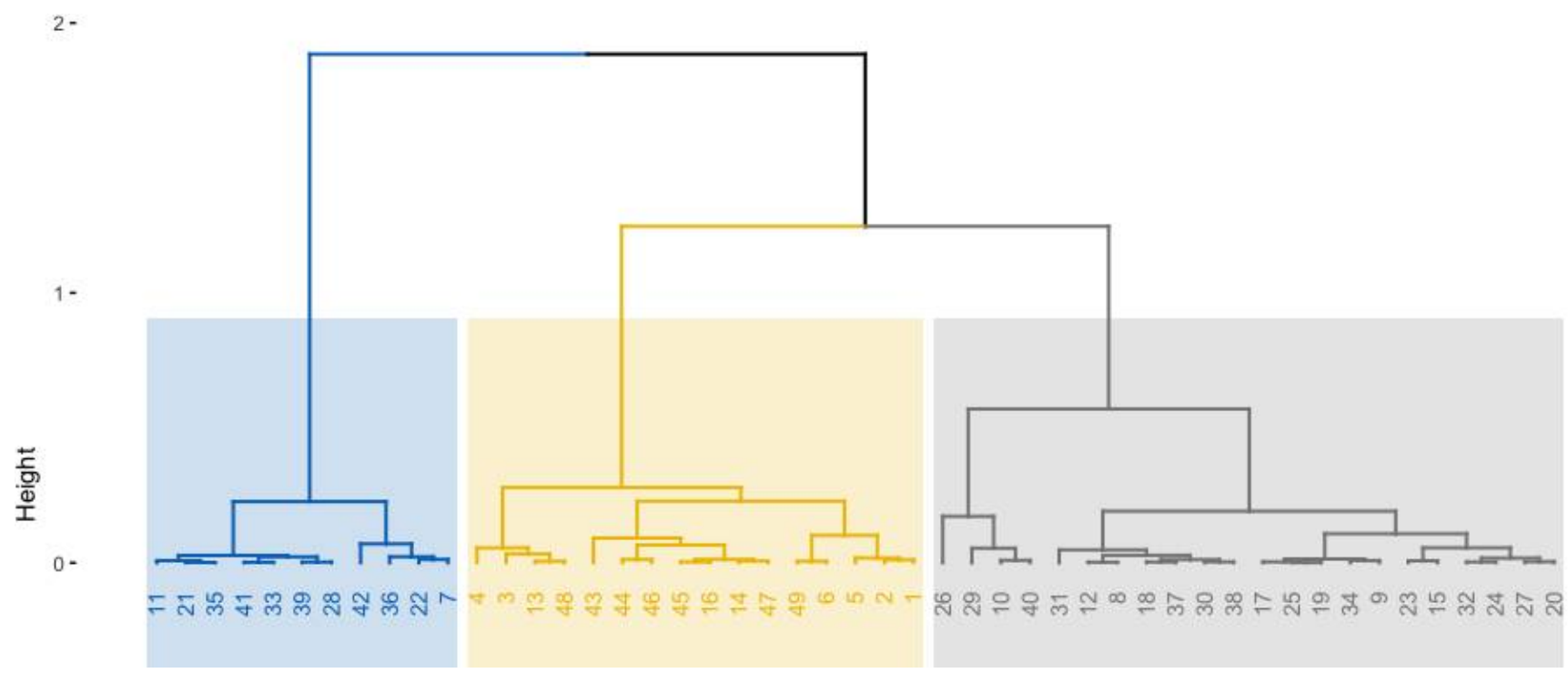

Fig. 4. Dendrogram of cluster analysis of 49 biofortified and late blight tolerant potato germplasm classified according to all the traits studied.

Thus, an improvement-breeding program involving such different cultivars may yield transgressive and heterotic segregants. Those selected clones will be used in the breeding programme after further evaluation.

\section{Conclusion}

The genetic variability among the CIP biofortified and late blight tolerant materials allows us to help the parental selection and pave the way to fortify and select blight tolerant potato for food security. The present study explored high level of morphological variation for market preferable tuber size, shape and yield among the accessions. Based on consumer preferences CIP403, CIP404, CIP405, CIP413 and CIP445 accessions present in cluster III were superior administered through the Deutsche Gesellschaft für Internationale Zusammenarbeit (GIZ) Fund for International Agricultural Research (FIA), contract number: 81219432. We also thank to International Potato Center (CIP), Lima, Peru for providing biofortified potato germplasm to TCRC, BARI for conducting the research.

\section{Authors' contributions}

Md. Mushfiqur Rahman: Conceptualization, conducted the field experiments, investigation, methodology, writing original draft, formal analysis, supervision, validation, writing review and editing, Md. Nurul Amin: investigation, data analysis and drafted the part of manuscript Md. Harunor Rashid: advice and suggest to interpret the results. Md. Mazadul Islam: helped in planning, designing and 
Table 4. Cluster means for eight characters in 49 CIP biofortified and late blight tolerant potato genotypes

\begin{tabular}{|c|c|c|c|c|c|c|c|c|c|}
\hline Cluster & $\begin{array}{l}\text { Para } \\
\text { meters }\end{array}$ & $\begin{array}{c}\text { Germinat } \\
\text { ion } \\
\text { percent }\end{array}$ & $\begin{array}{l}\text { Foliage } \\
\text { coverage } \\
\text { (1-9 scale) }\end{array}$ & $\begin{array}{c}\text { Stem / } \\
\text { hill } \\
\text { (no.) }\end{array}$ & $\begin{array}{c}\text { Plant } \\
\text { Height } \\
\text { (cm) }\end{array}$ & $\begin{array}{c}\text { Plant } \\
\text { vigor } \\
(1-9 \\
\text { scale })\end{array}$ & $\begin{array}{c}\text { Tuber } \\
\text { weight / } \\
\text { plant (g) }\end{array}$ & $\begin{array}{c}\text { Tuber } \\
\text { Count/10 } \\
\text { plant (no.) }\end{array}$ & $\begin{array}{l}\text { Yield / } \\
10 \text { plant } \\
\text { (g) }\end{array}$ \\
\hline \multirow{4}{*}{ Class I } & Min & 11.11 & 4.00 & 1.00 & 43.34 & 4.00 & 1.88 & 93.33 & 46.80 \\
\hline & Max & 86.67 & 8.00 & 1.67 & 76.08 & 7.00 & 5.68 & 329.00 & 189.40 \\
\hline & Mean & 46.44 & 5.45 & 1.30 & 60.55 & 5.64 & 3.84 & 194.45 & 127.81 \\
\hline & std & 27.64 & 1.04 & 0.26 & 10.92 & 0.92 & 1.23 & 75.90 & 46.96 \\
\hline \multirow{4}{*}{ Class II } & Min & 36.36 & 7.00 & 1.00 & 52.00 & 7.00 & 2.21 & 118.63 & 70.10 \\
\hline & Max & 90.91 & 9.00 & 4.42 & 105.80 & 9.00 & 5.58 & 474.67 & 246.00 \\
\hline & Mean & 66.70 & 7.86 & 1.42 & 86.61 & 8.05 & 3.84 & 224.48 & 158.78 \\
\hline & std & 19.02 & 0.47 & 0.73 & 14.86 & 0.72 & 1.06 & 76.46 & 47.46 \\
\hline \multirow{4}{*}{ Class III } & Min & 21.43 & 5.00 & 1.00 & 62.67 & 6.00 & 6.93 & 65.38 & 158.13 \\
\hline & Max & 100.00 & 9.00 & 2.58 & 101.60 & 9.00 & 14.35 & 189.00 & 332.80 \\
\hline & Mean & 62.04 & 7.56 & 1.31 & 82.22 & 7.94 & 10.05 & 121.22 & 229.88 \\
\hline & std & 24.38 & 0.96 & 0.44 & 13.90 & 1.06 & 2.47 & 34.78 & 57.31 \\
\hline
\end{tabular}

Table 5. Percentage of different CIP biofortified and late blight resistant potato accession grades of minituber by weight

\begin{tabular}{|c|c|c|c|c|c|}
\hline \multirow{2}{*}{ Accession Name } & \multicolumn{5}{|c|}{ Weight percentage } \\
\hline & $<5 \mathrm{~mm}$ & $5-10 \mathrm{~mm}$ & $15-20 \mathrm{~mm}$ & $20-25 \mathrm{~mm}$ & $>25 \mathrm{~mm}$ \\
\hline CIP-401 & 0.27 ijklmn & $1.68 \mathrm{rs}$ & $14.63 \mathrm{q}$ & 22.28 1nopq & $52.78 \mathrm{c}$ \\
\hline CIP-402 & 0.23 klmnopqr & $1.62 \mathrm{rs}$ & $15.25 \mathrm{q}$ & 22.13 opqr & $50.40 \mathrm{~cd}$ \\
\hline CIP-403 & $0.12 \mathrm{~s}$ & $1.18 \mathrm{~s}$ & $8.03 \mathrm{r}$ & $15.38 \mathrm{tu}$ & $71.37 \mathrm{a}$ \\
\hline CIP-404 & 0.17 opqrs & $1.42 \mathrm{rs}$ & $8.26 \mathrm{r}$ & 20.42 qrs & $66.30 \mathrm{~b}$ \\
\hline CIP-405 & 0.15 pqrs & $1.44 \mathrm{rs}$ & $15.37 \mathrm{q}$ & $35.64 \mathrm{~cd}$ & $40.93 \mathrm{hi}$ \\
\hline CIP-406 & 0.28 hijklm & 2.43 pqrs & 21.85 nop & $39.85 \mathrm{ab}$ & $22.61 \mathrm{mno}$ \\
\hline CIP-407 & 0.35 fghi & 3.31 opqrs & 21.76 nop & $28.05 \mathrm{fgh}$ & $37.65 \mathrm{ij}$ \\
\hline CIP-408 & 0.24 klmnop & $3.47 \mathrm{opqr}$ & $12.93 \mathrm{q}$ & $42.44 \mathrm{a}$ & $32.86 \mathrm{k}$ \\
\hline CIP-409 & 0.19 mnopqrs & $6.34 \mathrm{ijklm}$ & 31.56 cde & $18.29 \mathrm{rst}$ & 20.26 nop \\
\hline CIP-410 & 0.21 mnopqr & 9.73 def & $37.63 \mathrm{ab}$ & 23.42 jklmnopq & 5.64 uvwx \\
\hline CIP-411 & 0.32 ghijk & 7.54 ghijkl & 28.08 fghij & $36.07 \mathrm{bc}$ & 7.48 uvw \\
\hline CIP-412 & 0.23 klmnopq & 4.49 mnop & $23.56 \operatorname{lmno}$ & $34.92 \mathrm{~cd}$ & $27.36 \mathrm{l}$ \\
\hline CIP-413 & 0.14 qrs & 2.63 pqrs & $19.26 \mathrm{p}$ & 23.10 klmnopq & 42.86 fgh \\
\hline CIP-414 & 0.17 opqrs & 3.41 opqr & 28.44 efghi & 26.05 ghijklmn & $25.46 \mathrm{~lm}$ \\
\hline CIP-415 & $0.53 \mathrm{bc}$ & 8.07 fghi & $39.53 \mathrm{a}$ & 20.47 qrs & $14.10 \mathrm{qrs}$ \\
\hline CIP-416 & 0.17 opqrs & 4.52 mnop & 25.33 ijklm & 25.55 ghijklmno & $24.90 \mathrm{~lm}$ \\
\hline CIP-417 & 0.28 ijklmn & 4.40 mnop & 27.62 ghijk & 26.53 ghijkl & 27.781 \\
\hline CIP-418 & 0.25 jklmnop & 7.25 ghijkl & 27.48 ghijk & $35.79 \mathrm{c}$ & $12.47 \mathrm{rs}$ \\
\hline CIP-419 & 0.221 mnopqr & $5.68 \mathrm{klmn}$ & 30.88 cdefg & 31.89 def & $13.11 \mathrm{rs}$ \\
\hline CIP-420 & 0.36 fghi & $10.51 \mathrm{de}$ & $37.65 \mathrm{ab}$ & 19.74 qrs & 4.21 wxy \\
\hline CIP-421 & $0.50 \mathrm{~cd}$ & 9.44 defg & 30.36 defgh & 21.75 opqr & $11.52 \mathrm{st}$ \\
\hline CIP-422 & 0.41 defg & $1.85 \mathrm{rs}$ & 28.65 efghi & $42.27 \mathrm{a}$ & $12.93 \mathrm{rs}$ \\
\hline CIP-423 & $0.61 \mathrm{~b}$ & 6.42 hijklm & $34.32 \mathrm{bc}$ & 26.91 ghijk & $0 \mathrm{z}$ \\
\hline CIP-424 & 0.34 fghij & 7.70 fghijk & $25.60 \mathrm{ijkl}$ & 24.79 hijklmnop & 20.49 nop \\
\hline CIP-425 & 0.23 klmnopq & 8.12 efghi & 24.92 jklmn & $27.70 \mathrm{gh}$ & 19.55 op \\
\hline CIP-426 & 0.18 nopqrs & $5.69 \mathrm{klmn}$ & 24.68 jklmn & $39.66 \mathrm{ab}$ & $15.69 \mathrm{qr}$ \\
\hline CIP-427 & 0.39 efgh & $10.54 \mathrm{de}$ & 28.38 efghij & 20.70 pqrs & $9.89 \mathrm{stu}$ \\
\hline CIP-428 & 0.27 ijklmn & 9.43 defg & $21.91 \mathrm{mnop}$ & 32.68 cde & $5.37 \mathrm{vwx}$ \\
\hline CIP-429 & 0.26 ijklmno & $26.34 \mathrm{a}$ & 21.55 nop & $3.86 \mathrm{v}$ & $3.47 \mathrm{xyz}$ \\
\hline CIP-430 & 0.19 mnopqrs & 8.26 efghi & 29.83 defgh & $17.60 \mathrm{st}$ & 27.401 \\
\hline CIP-431 & 0.23 klmnopq & 7.89 fghij & $32.38 \mathrm{~cd}$ & $34.94 \mathrm{~cd}$ & $0 \mathrm{z}$ \\
\hline CIP-432 & 0.31 hijkl & $14.98 \mathrm{c}$ & $40.67 \mathrm{a}$ & $11.92 \mathrm{u}$ & $1.43 \mathrm{yz}$ \\
\hline CIP-433 & 0.24 klmnopq & 8.36 efghi & $32.84 \mathrm{~cd}$ & 20.21 qrs & $23.97 \mathrm{lmn}$ \\
\hline CIP-434 & 0.21 mnopqrs & 6.50 hijklm & $26.14 \mathrm{ijkl}$ & 29.30 efg & $17.47 \mathrm{pq}$ \\
\hline CIP-435 & 0.24 klmnop & $11.61 \mathrm{~d}$ & 30.758 defgh & 20.96 pqrs & 8.54 tuv \\
\hline CIP-436 & 0.23 klmnopq & 5.79 jklmn & 28.80 efghi & 26.19 ghijklm & $22.73 \mathrm{mno}$ \\
\hline CIP-438 & 0.46 cde & $8.60 \mathrm{efgh}$ & 27.34 hijk & 27.31 ghi & $12.72 \mathrm{rs}$ \\
\hline CIP-439 & 0.23 klmnopq & $6.32 \mathrm{ijklm}$ & 20.28 op & $21.91 \mathrm{opqr}$ & $37.83 \mathrm{ij}$ \\
\hline CIP-440 & 0.44 cdef & $11.06 \mathrm{~d}$ & 23.29 lmno & 27.03 ghij & 19.85 op \\
\hline CIP-441 & 0.19 mnopqrs & 5.48 lmno & $24.27 \mathrm{klmn}$ & $15.65 \mathrm{tu}$ & $37.96 \mathrm{ij}$ \\
\hline CIP-442 & 0.221 mnopqr & 8.37 efghi & 31.52 cdef & 26.93 ghijk & $13.44 \mathrm{rs}$ \\
\hline CIP-443 & $0.85 \mathrm{a}$ & $18.35 \mathrm{~b}$ & 30.75 defgh & $6.61 \mathrm{v}$ & $0 \mathrm{z}$ \\
\hline CIP-444 & $0.12 \mathrm{~s}$ & $5.05 \mathrm{mno}$ & $15.67 \mathrm{q}$ & 25.38 hijklmno & $42.35 \mathrm{gh}$ \\
\hline CIP-445 & $0.13 \mathrm{rs}$ & 5.49 lmno & $15.33 \mathrm{q}$ & 23.53 ijklmnopq & $43.27 \mathrm{fgh}$ \\
\hline CIP-446 & 0.18 nopqrs & $4.06 \mathrm{nopq}$ & 23.10 lmno & $34.18 \mathrm{~cd}$ & $26.07 \mathrm{~lm}$ \\
\hline CIP-447 & 0.24 klmnop & 3.46 opqr & 20.56 op & 26.44 ghijkl & $35.68 \mathrm{jk}$ \\
\hline CIP-448 & 0.24 klmnop & $2.56 \mathrm{pqrs}$ & $15.32 \mathrm{q}$ & 22.83 lmnopq & 49.13 cde \\
\hline CIP-449 & 0.19 mnopqrs & 2.04 qrs & $14.54 \mathrm{q}$ & 27.18 ghij & $46.68 \mathrm{def}$ \\
\hline
\end{tabular}




\begin{tabular}{|c|c|c|c|c|c|}
\hline CIP-450 & 0.23 klmnopq & 5.43 lmno & $15.19 \mathrm{q}$ & 22.48 mnopq & 46.05 efg \\
\hline CV (\%) & 21.28 & 20.36 & 8.653 & 9.252 & 9.55 \\
\hline Mean & 0.279 & 6.637 & 24.75 & 25.69 & 24.84 \\
\hline
\end{tabular}

Means followed by different letters are significantly different from each other

setting the experiment. Md. Mohi Uddin and Bimal Chandra Kundu: assisted in troubleshooting, provided constructive comments, suggestions and technical support to conduct the experiment. EHMS Rahaman: writing review and editing resources.

\section{Conflict of interests}

Authors declare that no conflict of interests exists regarding the publication of this paper.

\section{Supplementary files}

Table 1. Morphological characters of biofortified potato varieties.

Table 2. Code for different morphological characters of CIP biofortified and late blight tolerant accessions with shannon index.

Fig. 1. Selected Biofortified accessions for hybridization programme.

\section{References}

1. Ritchie H, Reay DS, Higgins P. Quantifying, projecting and addressing India's hidden hunger. Frontiers in Sustainable Food Systems. 2018 Apr 30;2:11. https://doi.org/10.3389/fsufs.2018.00011

2. Bouis HE, Welch RM. Biofortification-a sustainable agricultural strategy for reducing micronutrient malnutrition in the global south. Crop Science. 2010 Mar;50:S-20.

https://doi.org/10.2135/cropsci2009.09.0531

3. Gupta DS, Thavarajah D, Ekanayake LJ, Johnson C, Amarakoon D, Kumar S 2015. Rice, Wheat and Maize Biofortification. In: Lichtfouse E., Goyal A. (eds.) Sustainable Agriculture Reviews. Sustainable Agriculture Reviews, Vol. 16. Springer, Cham. https://doi.org/10.1007/978-3-319-16988-0_6

4. Ahmed MB, Akhter MS, Hossain M, Islam R, Choudhury TA, Hannan MM, Razvy MA, Ahmad I. An efficient Agrobacterium-mediated genetic transformation method of lettuce (Lactuca sativa L.) with an aphidicidal gene, Pta (Pinellia ternata Agglutinin). Middle-East Journal of Scientific Research. 2007;2(2):155-60. https://citeseerx.ist.psu.edu

5. Pushkarnath, 1976. Potato in Sub-tropics. Orient Longman.

6. Bartolome VI, Quintana LC, Olea AB, Paunlagui LC, Ynalvez MA, Maclaren CG. Experimental design and data analysis for agricultural research. Vol. 2. Training Documents. Biometrics Unit. International Rice Research Institute. 1999.

7. Afuape SO, Okocha PI, Njoku D. Multivariate assessment of the agromorphological variability and yield components among sweet potato (Ipomoea batatas (L.) Lam) landraces. African Journal of Plant Science. 2011 Feb 28;5(2):123-32. https://doi.org/10.5897/AJPS.9000176

8. Sivakumar P, Ray R, Panda S, Naskar S. Application of principal components analysis for sensory characterization of sweet potato curd. Journal of Root Crops. 2007;33(1):62-66.
9. Hornakova O, Zavodna M, Zakova M, Kraic J, Debre F. Diversity of common bean landraces collected in the western and eastern Carpatien. Czech Journal of Genetics and Plant Breeding-UZPI (Czech Republic). 2003. https://doi.org/10.17221/3723-CJGPB

10. Omokhafe KO, Alika JE. Multivariate of agronomic data on Hevea brasiliensis. In Proceeding of SUSANIBS Meeting 1999 Aug 23 pp. 168-173.

11. Nassir A. Studies on Genotype X Environment Interactions Variability and Plant Character Correlation in Rice (Doctoral dissertation, PhD Thesis, University of agriculture, Abeokuta, Nigeria).

12. MPONDA OK, Morse S, Gibbon D, ARTHUR AE. Genetic studies on seedling vigour in sesame. Annals of Applied Biology. 1997 Aug;131(1):161-70 https://doi.org/10.1111/j.1744-7348.1997.tb05403.x

13. Ahmadizadeh $\mathrm{M}$, Felenji H. Evaluating diversity among potato cultivars using agro-morphological and yield components in fall cultivation of Jiroft area. AmericanEurasian Journal of Agricultural and Environmental Sciences. 2011;11(5):655-62. http://www.idosi.org/.../9.pdf

14. Nestel P, Bouis HE, Meenakshi JV, Pfeiffer W. Biofortification of staple food crops. The Journal of Nutrition. $\quad 2006 \quad$ Apr $\quad 1 ; 136(4): 1064-67$. https://doi.org/10.1093/jn/136.4.1064

15. Siopongco LB, Altoveros NC, Cruz VM, Villavicencio ML. Morphological diversity in NPGRL's local corn collection. Philippine Journal of Crop Science. 1999;24(2/3):103-13.

16. Lê S, Josse J, Husson F. FactoMineR: an R package for multivariate analysis. Journal of statistical Software. 2008 Mar 18;25(1):1-8. https://doi.org/10.18637/jss.v025.i01

17. Kassambara A. Practical guide to principal component methods in R: PCA, M (CA), FAMD, MFA, HCPC, factoextra. Sthda; 2017 Aug 23.

18. Peterson BG, Carl P, Boudt K, Bennett R, Ulrich J, Zivot E, Cornilly D, Hung E, Lestel M, Balkissoon K, Wuertz D. Package 'performanceanalytics'. R Team Cooperation. 2018.

19. Mahalanobis PC. Mahalanobis distance. InProceedings National Institute of Science of India 1936 (Vol. 49, No. 2, pp. 234-256).

20. Rao CR, Rao CR, Statistiker M, Rao CR, Rao CR. Linear statistical inference and its applications. New York: Wiley; 1973 Feb.

21. Aytac S, Esendal E. An investigation on yield and some yield components of potato cultivars grown surroundings Samsun Ondokuz Mayis University. Journal of the Faculty of Agriculture. 1966;11:197-208.

22. Ruiz de Galarreta JI, Ezpeleta B, Pascualena J, Ritter E. Combining ability and correlations for yield components in early generations of potato breeding. Plant Breeding. 2006; 125(2):183-86. https://doi.org/10.1111/j.14390523.2006.01181.x

23. Placide R, Shimelis H, Laing M, Gahakwa D. Application of principal component analysis to yield and yield related traits to identify sweet potato breeding parents. Trop Agric. 2015;92:1-5. https://journals.sta.uwi.edu/ojs/index.php/ta/article/view/ 885

24. Islam MN, Hossain MA, Uddin MS. Phenotypic diversity of coconut germplasm conserved at different stations of BARI. Bangladesh Journal of Agricultural Research. 2009;34(1):25-31. https://doi.org/10.3329/bjar.v34i1.5749

25. Karuri HW, Ateka EM, Amata R, Nyende AB, Muigai AW, Mwasame E, Gichuki ST. Evaluating diversity among Kenyan sweet potato genotypes using morphological and 
SSR markers. Int J Agric Biol 2010 Jan 1;12(1):33-8. http:// www.fspublishers.org/published

26. Singh K, Bahal VK. Performance of TPS (True Potato Seeds) families for ware Potato production in Northeast hills. Journal of Indian Potato Association. 1997;24(3):14853.

27. Kadian MS, Patel PK, Thakur KC, Upadhya MD. Comparative yield potential of seedling tubers from true potato seed in Deesa (Gujrat). J Indian Potato Assoc. 1988;15(1):15-18.

28. Pandey JK, Reddy KR, Kumar AP, Singh RP. An overview on the degradability of polymer nanocomposites. Polymer degradation and stability. 2005 May 1;88(2):234-50. https:// doi.org/10.1016/j.polymdegradstab.2004.09

29. Karaca E. A study on some phenologic, morphologic, agronomic and technologic characters of different originated Potato collected surrounding Ordu City. Unpublished Master Thesis, Ondokuz Mayıs University, Turkey. 2004.

\section{Additional information}

Peer review information: Plant Science Today thanks Sectional Editor and the other anonymous reviewers for their contribution to the peer review of this work.

Reprints and permissions information is available at

https://horizonepublishing.com/journals/index.php/PST/open_access_policy

Publisher's Note: Horizon e-Publishing Group remains neutral with regard to jurisdictional claims in published maps and institutional affiliations.

To cite this article: Rahman M M, Amin M N, Rashid M H, Islam M M, Kundu B C, Uddin M M, Rahaman E H M S. Genetic variation among biofortified and late blight tolerant potato (Solanum tuberosum L.) (mini tuber) production in Bangladesh. Plant Science Today. 2021;8(3):647-654. https:// doi.org/10.14719/pst.2021.8.3.1170

Plant Science Today, published by Horizon e-Publishing Group, is covered by Scopus, Web of Science, BIOSIS Previews, Clarivate Analytics, etc. See https://horizonepublishing.com/journals/index.php/PST/indexing_abstracting 